\title{
LA UTOPÍA SOCIOEPISTÉMICO-TECNOLÓGICA DE BACON. LA NUEVA ATLÁNTIDA
}

\section{BACON'S SOCIO EPISTEMIC-TECNOLOGICAL UTOPIA. THE NEW ATLANTIS}

\author{
Diana Solano Villarreal \\ Universidad Nacional \\ artemisa_d@yahoo.com \\ Recibido: 28/03/2017 - Aprobado: 16/09/2017
}

\begin{abstract}
Resumen
Este artículo estudia la posición de F. Bacon respecto a la utopía de la Nueva Atlántida, desde su libro que lleva el mismo nombre y desde El Novum Organum, La Instauratio Magna y De la sabiduría egoísta, obras del mismo autor, desde la perspectiva decolonial modernidad/ colonialidad, específicamente la teoría de la modernidad bipolar del Dr. Bernal Herrera. Aquí se explica cuáles son, a mi entender, las verdaderas características de la utopía de Francis Bacon.
\end{abstract}

Palabras clave: Bacon, utopía, modernidad/colonialidad

\section{Summary}

This article examines the position F. Bacon about the utopia of The New Atlantis, from the latter and Novum Organum, The Instauratio Magna and Wisdom of selfish author, from the perspective-colonial modernity / coloniality, specifically theory Bipolar Modernity Dr. Bernal Herrera. This explains what we believe the true characteristics of the utopia of Francis Bacon.

Keywords: Bacon, Utopia, Modernity/Coloniality.

"Ahora bien, de toda la filosofía de los griegos y de las ciencias particulares que derivaron de ella, a duras penas se puede, después de un lapso de tantos años, aducir un solo experimento realmente aceptable que haya contribuido a aliviar y mejorar el estado del hombre, o que pueda aprovecharse para las especulaciones y dogmas de la filosofía (...) por lo cual, del mismo modo que en religión se nos previene y se 
nos recomienda que nuestra fe se eche a ver en nuestras obras, así puede aplicarse esto muy oportunamente a la filosofía juzgándola por sus frutos y dando por vana aquella que sea estéril: muy especialmente en el caso de que, en lugar de frutos de vid y de oliva, produzca cardos y espinas de disputas y contiendas"

Bacon, 1991, XXIII

\section{Introducción}

Este artículo estudia la posición de Bacon respecto del vulgo en los libros La Nueva Atlántida, El Novum Organum, La Instauratio Magna y De la sabiduría egoísta. Aquí se explica cuáles son, a mi entender, las verdaderas características de la utopía de Francis Bacon.

La perspectiva teórica desde la cual realizaré la investigación propuesta es la que corresponde a la teoría de la modernidad bipolar del Dr. Bernal Herrera. Esta teoría, que se encuentra dentro de la corriente modernidad/colonialidad, postula que "la modernidad es un proceso único, pero articulado alrededor de dos polos distinguibles aunque interdependientes" (Herrera, 2007, p. 20). La modernidad, entonces, presenta un doble conjunto de objetivos, una doble agenda, definida por la diversa articulación de los tres ejes básicos de la modernidad como proceso global: conocimiento, control y liberación. Su polo metropolitano implementó una agenda que incluía algunos procesos liberadores, tan reales como parciales, basados en un conocimiento que incrementó el control de la realidad (Herrera, 2007).

Ahora bien, ¿cómo se relaciona la teoría de la modernidad bipolar con los escritos de Francis Bacon? Pienso que en los planteamientos epistemológicos baconianos se deja muy claro que el método que allí se expone no es para todos, y de ello podemos inferir que no todos están calificados para tener acceso a la verdad. En el polo metropolitano se dieron procesos liberadores basados en el conocimiento, los cuales no siempre fueron totales o completos, y en el polo colonial menos aún, pues no fueron pensados para ellos.

Francis Bacon es el más famoso y beligerante promotor de las ideas provenientes del Renacimiento, quien además creía firmemente que el conocimiento obtenido mediante el método correcto (su método inductivo) podía generar grandes beneficios al mundo. La naturaleza, ente misterioso y temido por el ser humano desde su aparición en el planeta, se podía estudiar, comprender y sistematizar realizando experimentos y extrayendo conclusiones 
a partir de las evidencias obtenidas, siguiendo el ya mencionado método inductivo. Bacon alegaba que, con un grupo de ingenios bien adiestrados, la investigación inductiva conduciría a la verdad.

La vertiente utópica de New Atlantis: A Work Unfinished (1627) fue una de las herramientas que Bacon eligió para enunciar sus ideas. La Nueva Atlántida es la descripción de una sociedad fantástica en la que se desarrollaba el proyecto socioepistémico-tecnológico del filósofo inglés, cuya misteriosa civilización llamada Bensalem se yergue como un paraíso social donde sus miembros se cuidan mutuamente y los conflictos civiles son desconocidos.

En el puesto central de esa sociedad ideal se encuentra una institución conocida como Casa de Salomón, una especie de instituto de estudio e investigación creado a partir del financiamiento del aristócrata y astrónomo danés Tycho Brahe (la idea de Bacon inspiró la creación de la Royal Society of London for Improving Natural Knowledge). Los miembros de la Casa de Salomón obtienen bonanzas científicas enormes gracias al método inductivo y a su sistema de recopilación de datos alrededor del mundo. Luego toman los datos recopilados, los ordenan, sistematizan y extraen de ellos avances científicos.

Tal era el de la fundación e institución de una orden o sociedad que nosotros llamamos Casa de Salomón, la asociación más noble según creemos sobre la tierra y que es el faro de este reino. Está dedicada al estudio de las obras y criaturas de Dios... esta orden o sociedad es a veces llamada Casa de Salomón, y a veces Colegio de las Obras de los Seis Días (Bacon, 1991, p. 198).

Esta Casa de Salomón, que se caracteriza por dedicarse "al estudio de las obras y creaturas de Dios", además es una orden o sociedad que es el pilar de la utopía socioepistémico-tecnológica del filósofo inglés. En ella se crean todos los conocimientos que proveen a Bensalem de su extraordinario bienestar material. En esta sociedad se dan "adelantos tecnológicos" con los cuales en la Europa de aquel tiempo (siglos XVI Y XVII) la mayoría de las personas no podían ni soñar. Se mencionan artefactos tan fantásticos como submarinos, y al final de la segunda parte Bacon lista una serie de conquistas de la ciencia sobre la naturaleza tales como: retardo del envejecimiento, cura para enfermedades en ese tiempo incurables, prolongación de la vida, entre otras. 
El Colegio de los Seis Días es visto por los mismos habitantes de la utópica isla (la Nueva Atlántida) como "el faro" de su reino, como aquello que les da la luz y guía necesaria en un mar de oscuridad. Esta alusión al "faro" evidencia la posterior consigna de la Ilustración, de la razón (y el conocimiento que esta ayudará a producir) como una luz. Es decir, todo de lo que se enorgullecen los bensalemientes, todo su bienestar material, emana de esta casa de investigación.

Pero, además es importante hacer énfasis en que Bensalem se yergue no solo como un paraíso tecnológico, sino también social, donde sus integrantes velan unos por los otros y las contiendas civiles se desconocen, lo que sugiere que Francis Bacon consideraba que un bienestar y comodidad material proporcionado por los adelantos tecnológicos implicaría necesariamente un espacio social solidario y libre de conflictos de corte civil.

La anterior no es una idea descabellada. Una sociedad donde las necesidades básicas (alimentación, vestido y techo) se encuentran colmadas y (si la economía del Estado lo permite) se pueden dar algunas otras prerrogativas socioeconómicas, como un instituto de investigación como la Casa de Salomón, costeada por el Estado, existen muchas menos posibilidades de sufrir conflictos sociales. No obstante, condiciones socioeconómicas favorables para los pueblos no garantizan la ausencia de complicaciones civiles.

La certeza de F. Bacon respecto a la armonía general puede deberse a una antropología optimista, cosa extraña porque el filósofo inglés tenía suficiente conocimiento de hasta dónde puede llegar un ser humano con o sin recursos económicos suficientes, o porque asumía que una sociedad guiada por el conocimiento permitiría o procuraría mantener algunas de las características menos agradables del ser humano, tales como la envidia y la codicia (tratada en trabajos como De la sabiduría egoísta), por lo menos controladas. Como sea, en el texto de La Nueva Atlántida no se dan mayores detalles respecto a cómo un Gobierno guiado (no ejercido) por científicos (diríamos hoy) puede llegar a tal punto de armonía social.

Otro dato curioso respecto a este "faro" que ilumina a los benselemitas es que es una "asociación". Es decir, no cualquiera puede pertenecer a ella. Hace falta poseer ciertos atributos para poder ostentar el título de miembro de la Casa de Salomón. Lo que les envestirá de toda clase de honores y privilegios: 
Después que la ceremonia ha terminado, el padre o Tirsán se retira y algún tiempo después vuelve otra vez para la cena. Y se sienta solo bajo el dosel, como antes, y ninguno de sus descendientes se sienta con él, no importan en su grado o dignidad, a menos que sea de la Casa de Salomón (Bacon, 1991, p. 201).

Entre las cosas más importantes de los miembros de esta asociación de "científicos" es que se les considera como "iluminados" poseedores de ciertas características que los diferencian del resto, al punto de que su sola presencia es objeto de reverencia. Ahora bien, ¿qué características debe poseer una persona para pertenecer a esta orden de sabios? Nuevamente en La Nueva Atlántida (1626) no se menciona con detalle. Lo anterior al igual que otros detalles que solo se citan o no se desarrollan suficiente, tal vez sea consecuencia de la muerte de Sir Francis Bacon en 1626, por lo cual de hecho no pudo terminar la composición de su utopía.

Empero, El Novum Organon nos da una pista de qué características debería poseer una persona para formar parte de este grupo de sabios. Desde luego, como es de suponer, no se está hablando de una tipología sistematizada; se habla más bien de nociones generales, indicios dejados aquí y allá a lo largo de El Novum Organon, aunque ciertamente algunos de los vicios más críticos del ser humano, los idola, son explicados con mucho detalle. Me refiero claro a la teoría de los ídolos (la cual detallo en los artículos "El barón de Verulam y el vulgo" y "Epistemología y dominio en Francis Bacon"). Baste ahora con señalar que para el filósofo inglés las principales características que debe poseer un ser humano para pertenecer al "faro" de Bensalem son las mismas que se necesitarían para transitar los caminos del método baconiano: una inteligencia elevada, pues "las inteligencias elevadas son las que hacen progresar las ciencias" (Bacon, 1991, pp. 67-68) y desde luego "una mente purificada al estudio de los hechos" (p. 70), en otra palabras, una mente elevada y libre de los ídolos de la mente. Si la mente o el espíritu de una persona no se encuentra libre de la contaminación de los idola, no podrá buscar la verdad mediante la inducción baconiana, aún y cuando sea elevada.

Dentro de la asociación de la Casa de Salomón se dan -lo cual no es extraño ni para la antigüedad clásica, el medievo y desde luego tampoco para la modernidad-políticas para asegurarse la sucesión de los sabios: 
También tenemos -como debes pensar- novicios y aprendices, para que no falte sucesión a los hombres anteriormente empleados, aparte de gran número de sirvientes y ayudantes, hombres y mujeres. También nos consultamos cuáles de los inventos o experimentos que hemos descubierto deben publicarse, y cuáles no; y hacemos todos juramento de secreto para aquellos que pensamos conveniente mantener en secreto, aunque algunos de ellos los revelamos al Estado, y algunos no (Bacon, 1991, p. 210).

Los novicios o aprendices de este protoinstituto de investigación, ${ }^{1}$ como iniciados en sus saberes y en su método de purificación de la mente, hacen un juramento de secreto para asegurarse de que los conocimientos que se generen en la institución no sean revelados a nadie. Aquellos que producen saber se reservan el derecho de decidir qué, cuándo y cuánto se revela:

No está nuestra filosofía al alcance de la mano. No se la puede coger al paso; no se apoya en las premoniciones que halagan el espíritu; finalmente, no se la podrá poner al alcance del vulgo, a no ser por sus defectos y sus prácticas consecuencias (Bacon, 1991, p. 33).

El segmento anterior es especialmente claro respecto del carácter discriminatorio del método propuesto por Francis Bacon para adquirir conocimiento. El método inductivo (con todo lo que implica) no está hecho ni pensado para ser compartido con la mayoría de las personas, no se pretende que sea democratizado. Lo único que se espera que sea socializado es el fruto o frutos que ese entendimiento (de la naturaleza) pueda producir, pero nunca la forma en que se llegó a los ya mencionados alcances.

Resulta muy reveladora esta posición de Bacon acerca de su filosofía en lo referente a la epistemología, puesto que siempre se le ha entendido o se le ha querido entender como un "democratizador" del conocimiento (parte del mito del conocimiento de la modernidad), al estilo de Desiderio Erasmo o de Juan Luís Vives, quienes sí abogaron por compartir el saber con la mayor cantidad de individuos posibles (niños en este caso). Claro que Erasmo y

1 Digo instituto de investigación y no universidad porque no existía docencia, como sí existía en las universidades europeas durante la Edad Media y el Renacimiento. Incluso podemos ir más atrás hasta la Academia de Atenas, fundada por Platón alrededor del 388 a.C., considerada como la primera universidad de Europa, donde la docencia era de importancia crítica. Así mismo sucedía con el Liceo (fundado por Aristóteles en 335 d.C.), en el cual se conjugaban la investigación y la enseñanza. 
Vives esgrimieron una propuesta pedagógica y no un nuevo método epistémico como Bacon o Descartes, pero ambos pensadores del Renacimiento (Vives y Erasmo) creían que se debían socializar los conocimientos que se tenían en ese momento.

El barón de Verulam no se detuvo a formular una propuesta pedagógica de esta índole. Lo importante era crear un nuevo sistema epistémico para conseguir los saberes necesarios para mejorar la vida cotidiana de la mayor cantidad de personas posibles, pero el método para producir ciencia no es para ser socializado, “(...) no se le podrá poner al alcance del vulgo, a no ser por sus defectos y sus prácticas consecuencias” (Bacon, 1991, p. 33). El espíritu de una propuesta democratizadora de los saberes nunca iluminó a Bacon, por lo menos en lo que respecta a su método epistémico.

Es más, sus secretos son tales que ni siquiera los revelan todos al Estado. En el seno del "faro" se decide qué será compartido y qué no y al parecer tienen la autonomía para eso y tal vez para algo más, pues en el texto de $\mathrm{La}$ Nueva Atlántida no se menciona que el Estado se encuentre disconforme con lo anterior y se conforma con la información que se le quiera dar, sin pedir o exigir más.

El cultivo de las ciencias y el precio de ese cultivo, no están en una misma mano; las inteligencias elevadas son las que hacen progresar las ciencias; pero el precio y las recompensas de sus trabajos están en manos del pueblo y de los príncipes, que, salvo muy raras excepciones, son medianamente instruidos (Bacon, 1991, pp. 67-68).

La cita anterior constituye un ejemplo de las consecuencias de la preponderancia de las personas no instruidas o no instruidas adecuadamente en el avance de las ciencias. Las ciencias deben ser dirigidas por un grupo exclusivo de personas cultivadas fuera de la contaminación de las filosofías anteriores.

Empero, el aforismo XCI de El Novum Organon también nos proporciona un dato muy importante en lo referente a las razones que pudieron llevar a Bacon a mantener secretos aún con el Estado los progresos científicos en su última obra y por qué el cultivo de las ciencias se debe dar con el subsidio económico del Estado, pero sin ninguna inherencia de este último en el 
accionar y toma de decisiones en los institutos de investigación, en el caso de la Nueva Atlántida, de la Casa de Salomón. El aforismo continúa así:

Los progresos de este género, no sólo carecen de recompensa y no son remunerados por los hombres, si que también les falta los sufragios del público; como están, en efecto, por encima del alcance de la mayoría de los hombres, el viento de las opiniones populares las derriba y aniquila fácilmente. No debe maravillarnos, pues, lo que no ha sido honrado, no ha prosperado (Bacon, 1991, pp. 67-68).

Bacon supone que aún en su isla utópica las personas que estén al frente del Gobierno, al no ser "científicos", no comprenderán ni el método ni los alcances últimos de los descubrimientos que se den en la Casa de Salomón. A este respecto, puede que el vizconde de Saint Albain tuviera cierta razón, pues si vemos el caso de los Gobiernos actuales (los que tienen recursos económicos y humanos suficientes), si bien no controlan o dictan la totalidad de las investigaciones científicas y tecnológicas, sí que tienen una buena cuota de poder en las decisiones respecto a qué proyectos se financian y cuáles no. Y aunque desde luego se toman muy en cuenta las opiniones de los entendidos en esos menesteres, las decisiones que privan siguen siendo sobre todo políticas.

Los Gobiernos están controlados por políticos, no por científicos, y tal vez aquí es donde se hace más evidente la utopía de la Nueva Atlántida, en un Estado que financia investigaciones científicas sin hacer preguntas a la Casa de Salomón, confiando ciegamente en el buen juicio de los miembros de esta casa de investigación.

Pareciera que los miembros de la Casa de Salomón no tienen inclinación ni interés político de ninguna clase. Libres de los ídolos, lo único importante es experimentar, descubrir y mejorar materialmente la vida cotidiana de los seres humanos. No obstante, serán ellos quienes decidan qué se investiga, qué no y qué descubrimientos y avances tecnológicos le serán revelados al Gobierno de la isla y cuáles no, lo que deja cierto gusto a decisión política en el fondo. La desconfianza de Bacon hacia el vulgo, llámese gobierno o pueblo llano, se vuelve a hacer evidente. 
Por otra parte, la alusión de Bacon respecto a la poca instrucción del pueblo y de los príncipes es interesante. El pueblo inglés y europeo en general en los siglos XVI y XVII ciertamente estaba poco instruido, y si lo estaba era en las filosofías medievales que tanto desdeñaba Bacon; pero los príncipes (con quienes de una u otra forma el filósofo inglés trabajó) Isabel Tudor (Isabel I) y Jacobo I no.

La reina Isabel I no solo era una mujer muy inteligente, sino de hecho muy instruida, quien recibió una esmerada educación. Dominaba con elegancia y gracia su inglés natal, el francés, el italiano, el español, el griego y el latín, además de haber leído los clásicos griegos y romanos y los textos obligados de la patrística y la escolástica. Jacobo I por su parte tuvo también una excelente educación, supervisada por el historiador y poeta George Buchanan, erudito de gran prestigio.

Tal vez Bacon se refería justamente a la educación "clásica" de los monarcas anteriormente mencionados, o al hecho de que, ciertamente, la educación de todos los príncipes europeos no necesariamente era tan esmerada, y si lo era sería clásica. Si es por lo anterior, tiene todo el sentido la reticencia del barón de Verulam a compartir el método y sus resultados, simplemente no lo entenderían.

En este punto se puede decir que el proyecto epistemológico del Lord Canciller de Inglaterra debe presentar una sociedad del conocimiento dentro de un Estado. Esta Casa de Salomón que se caracteriza por dedicarse "al estudio de las obra y creaturas de Dios" además es una orden o sociedad, es decir, es un grupo y no se espera que lo que se investiga, y el método mediante el cual se hace, sea de conocimiento generalizado.

La última obra de Bacon nos deja claro que, en su filosofía, el conocimiento no se produce para ser compartido en su totalidad, ni siquiera con los habitantes de la sociedad a la cual pertenece. Solo se espera compartir los frutos de las investigaciones que pueden facilitar la vida cotidiana y nada más. La epistemología baconiana no fue concebida para que la mayoría practicara su método de conocimiento, sino para que tuvieran acceso a sus frutos.

Ahora bien, es importante detenernos en este punto, específicamente en el que tiene que ver con la utilidad de la filosofía. Cuando el filósofo inglés insiste en los frutos de las investigaciones, y en su utilidad para el vulgo no está pensando exclusivamente en la producción de cosas como fin último 
de la filosofía. Más bien, considera que hay una relación entre la utilidad y la idea de verdad, y que la utilidad debe ser buscada en esta correlación. La utilidad es la rúbrica de la verdad de la filosofía: "Las obras en sí mismas han de estimarse más en cuanto que son prendas de la verdad que por sus conveniencias para la vida" (Bacon, 1991, p. 81). Bacon ve en la utilidad el resultado de la verdad:

Pues el mecánico, sin preocupación alguna por verdad, no levanta su mente ni tiende su mano a cosa alguna que no esté subordinada a su trabajo. Más solamente habrá esperanzas bien fundadas de un progreso ulterior de las ciencias cuando se acepten y se reúnan en la historia natural muchos más experimentos que no son en sí de utilidad alguna y que se dirigen exclusivamente al descubrimiento de las causas y de los axiomas, a los cuales llamo yo lucíferos a diferencia de los fructíferos. Estos tales tienen en sí una virtud y condición admirable: a saber la de que nunca fallan ni se malogran. Pues siempre que se les emplee para esto, no para realizar algún trabajo particular sino para revelar la causa natural de alguna cosa, donde quiera que caigan, responden a su propósito, ya que deciden la cuestión (p. 71).

Aquí el mecánico es un miembro del vulgo, del común. Un individuo que se limita a realizar el trabajo con el que se gana la vida (labor que de hecho le debe consumir todas sus fuerzas físicas y mentales, pues no cuenta con el tiempo para reflexionar sobre otras cosas), pero no se detiene a pensar qué puede haber más allá. No se pregunta si cambiando algún procedimiento, si experimentando pudiera toparse con alguna verdad de la naturaleza y con ella continuar hacia nuevos descubrimientos que revelarían más verdades que, aunque en primera instancia no parezcan servir para el mejoramiento de la vida cotidiana, no se desperdician pues cualquier descubrimiento que nos acerque a la verdad, a la causa natural de algún fenómeno en la naturaleza, será de utilidad.

No obstante, mientras los individuos no exilien los ídolos de la mente, las personas continuarán trabajando mecánicamente en sus labores diarias sin ver más allá. 


\section{La religión y el Estado}

En Bensalem la población es mayoritariamente cristiana. Cristiana en tanto ve en Jesucristo a su señor y salvador, pero no parece ser católica, cosa que no extraña dado que para el tiempo de Bacon ya Inglaterra y él mismo eran protestantes anglicanos. Esta simple denominación de cristianos quizás incluya las dos partes que para el siglo XVII se encontraban en pugna en Europa Occidental: cristianos católicos romanos y cristianos protestantes.

Lo que sí queda claro es que hay una cierta o parcial libertad de culto, ya que a los judíos se les permite profesar su fe libremente, siempre y cuando muestren respeto hacia las creencias cristianas (Bacon, 1991). La religión judía parece ser la única permitida aparte claro del cristianismo, el cual no parece estar organizado, por lo menos en el nivel en que lo estaba la Iglesia católica. ${ }^{2}$

Sea como sea, los representantes de la Iglesia de Besalem (si se me permite utilizar el concepto), aunque tuvieran alguna influencia o poder en el Gobierno, no tenían injerencia alguna en las cuestiones relacionadas con la Casa de Salomón, pues, tal como se expresa en el aforismo LXII de El Novum Organum, Bacon (1991) desea evitar:

Una tercera especie de filósofos (...) que introduce en la filosofía la teología y las tradiciones, en nombre de la fe y de la autoridad. De entre éstos, algunos han llevado la locura hasta pedir la ciencia por invocaciones a los espíritus y a los genios (p. 48).

El influjo de las ideas religiosas o teológicas, provengan de una religión organizada o no, no son toleradas en el "faro" de la Nueva Atlántida. La ciencia debe permanecer libre de cualquier influencia externa a sí misma. Tal vez porque la Casa de Salomón era ya de por sí una suerte de sociedad cerrada de científicos a quienes se les veneraba como a altos sacerdotes (Bacon, 1991). Más adelante en el aforismo LXV se puede leer:

La filosofía corrompida por la superstición e invadida por la teología, es el peor de todos los azotes, y el más temible para los sistemas en conjunto o para sus diversas partes (...) Toda precaución para huir de tal peligro es poca; pues

2 O tal vez el rey sería la cabeza de la Iglesia, como en Inglaterra. 
la peor cosa del mundo, es la apoteosis de los errores, y debe considerarse como el primer azote del espíritu, la autoridad sagrada concedida a vanas ficciones. Algunos modernos han incurrido en ese defecto con tal ligereza, que han intentado fundar la filosofía natural sobre el primer capítulo del Génesis, el libro de Job, y otros tratados de la Santa Escritura, interrogando la muerte en medio de la vida. Es tanto más necesario que de la mezcla impura de las cosas divinas y las humanas, salga no sólo una filosofía quimérica, sí que también una religión herética. Es, pues, un precepto muy saludable, contener la intemperancia del espíritu, no dando a la fe sino lo que es materia de fe (pp. 50-51).

La ciencia debe mantenerse libre de cualquier contaminación. La ciencia (o nueva filosofía) es algo tan "puro e inmaculado" como la verdad que busca. Por ello, cualquier contacto con la teología o la religión, lejos de ayudar con el avance hacia la verdad, lo entorpecería, pues si los descubrimientos de la ciencia contradicen las Sagradas Escrituras, en el mejor de los casos, teólogos y religiosos mutilarían la nueva propuesta para hacerla calzar con lo expresado en la Biblia. En el peor de los casos, ocurriría lo que a la teoría heliocéntrica de Copérnico (1473 - 1543), la cual simplemente fue negada, pues contradecía las aseveraciones canonizadas de Aristóteles y Tholomeo. La ciencia es una cosa, la política otra y las cuestiones de fe otra, las tres muy diferentes (por lo menos para Bacon), cada una en su campo puede trabajar mejor.

\section{Conclusión}

La Nueva Atlántida no se yergue como una utopía solo por los fabulosos objetos con los que cuenta y el orden de la sociedad con la que cuenta la isla. La Nueva Atlántida es una utopía porque ni el Gobierno ni la religión ni el pueblo llano se inmiscuyen en los menesteres de la ciencia. La Casa de Salomón trabaja con recursos del Estado, pero se reserva el derecho de revelar u ocultar sus descubrimientos del propio Gobierno.

Por otra parte, aunque es un reino cristiano, los encargados de administrar la fe se limitan a eso, a los asuntos de la fe y nada más. Los miembros de la Casa de Salomón son prácticamente una sociedad cerrada cuyos miembros son admirados como altos sacerdotes (los que casi no se dejan ver), pero 
escogen jóvenes (en la obra en cuestión no se explica cómo o por qué) con determinadas características mentales que les permitan formar parte de la élite intelectual de Bensalem.

En todo caso algo queda absolutamente claro, el conocimiento que se produce en la Casa de los Seis Días no será para todos, solo los frutos de algunos de los descubrimientos serán revelados y dados al común para facilitarle la vida cotidiana. No obstante, por más generosa que parezca esta actitud, no deja de ser de dominio, ni todos los avances, ni el acceso a la vedad ni el método por el que se consigue son para todos. El común debe contentarse con lo que se le quiera ceder. El conocimiento es poder y el conocimiento en la Nueva Atlántida está concentrado en muy pocas manos.

\section{Referencias}

Bacon, F. (1991). Instauratio Magna, Novum Organum, Nueva Atlántida. México: Porrúa. Bacon, F. (2002). Novum Organum. Barcelona: Ediciones Folio.

Bacon, F. (2012). De la sabiduría egoísta. Madrid: Penguin Random House Grupo Editorial España.

Herrera, B. (2007). Las dos caras de la moneda: modernidad colonial y metropolitana. Pasos No 131 (Mayo-jun.- 2007). P 19-24. 